\title{
Simultaneous determination of saikosaponin derivatives in Bupleurum falcatum by HPLC-ELSD analysis using different extraction methods
}

\author{
Jungwon Choi ${ }^{1} \cdot$ Juree Kim ${ }^{1} \cdot$ Sam Sik Kang ${ }^{2} \cdot$ Sanghyun Lee $^{1}$
}

Received: 5 January 2021 / Accepted: 15 January 2021 / Published Online: 31 March 2021

(C) The Korean Society for Applied Biological Chemistry 2021

\begin{abstract}
Saikosaponin derivatives such as saikosaponins A, B1, B2, B3, B4, C, and D present in Bupleurum falcatum were analyzed by a high performance liquid chromatograph equipped with an evaporative light scattering detector, using different extraction solvents (water and $70 \%$ ethanol). The samples were injected into a YMC Pack Pro $\mathrm{C}_{18}$ column and separated using a gradient elution system with a mobile phase composed of acetonitrile and water at a flow rate of $1.1 \mathrm{~mL} / \mathrm{min}$. The content of saikosaponin derivatives was higher in $70 \%$ ethanol extract than in water extract. This study provides an efficient analytical method for determining the optimal conditions for extraction of saikosaponin derivatives, which can be used as a basis for development of functional foods and pharmaceutical products from B. falcatum.
\end{abstract}

Keywords Bupleurum falcatum · Extraction method · High performance liquid chromatograph - Quantitative analysis . Saikosaponin

\section{Introduction}

Recent pharmacological studies have shown that the medicinal herb, Bupleurum falcatum (BF), is effective in improving

Sanghyun Lee $(\bowtie)$

E-mail: slee@cau.ac.kr

${ }^{1}$ Department of Plant Science and Technology, Chung-Ang University, Anseong 17546, Republic of Korea

${ }^{2}$ Natural Products Research Institute and College of Pharmacy, Seoul National University, Seoul 08826, Republic of Korea

This is an Open Access article distributed under the terms of the Creative Commons Attribution Non-Commercial License (http://creativecommons. org/licenses/by-nc/3.0/) which permits unrestricted non-commercial use, distribution, and reproduction in any medium, provided the original work is properly cited. cognitive function [1,2]. BF has been used as a traditional herbal medicine for centuries. Ancient doctors in Korea used a variety of herbs to treat mental stress, which produced similar effects as described in BF [3]. In East Asia, it is being used to treat women's health problems, depression, digestive problems, hepatitis and infections [4-8]. Many studies have reported the presence of various bioactive components in its roots, such as polysaccharides, triterpenoid glycosides, phenethyl alcohol glycosides, and flavonoid glycosides [9-13].

Phytochemical studies have demonstrated that saikosaponins are the major components present in BF. Saikosaponins are oleananetype triterpenoid saponins and divided into seven types according to their characteristic aglycone moiety [14]. Saikosaponins can be broadly divided depending on the number of rings present, but generally five-ring structures tend to dominate [15]. Saikosaponins isolated from $\mathrm{BF}$ are known for their numerous pharmacological activities, including anti-inflammatory, anti-bacterial, anti-tumor, anti-cancer, anti-hepatitis, and anti-allergic [16-20].

In this study, we aimed to and quantify saikosaponins A, B1, B2, B3, B4, C, and D in BF extract using a high performance liquid chromatograph (HPLC) equipped with an evaporative light scattering detector (ELSD).

\section{Materials and Methods}

\section{Plant materials}

The 70\% ethanol (EtOH) (3-19-0097) and water (3-19-0054) extracts of $\mathrm{BF}$ were provided by Korea Institute of Oriental Medicine, Daejeon 34054, Republic of Korea.

\section{Instruments and reagents}

HPLC analysis was performed using an instrument (Gilson 72, Rue Gambetta-BP45 95400, Villers Le Bel France) equipped with a pump, auto-sampler, and ELSD. The HPLC grade solvents (water and acetonitrile) were used for analysis and purchased from J. T. Baker (Philipsburg, PA, USA). Analytical grade methanol 
$(\mathrm{MeOH})$ reagent was purchased from Samchun Pure Chemical Co., Ltd. (Pyeongtaek, Korea). Saikosaponins A, B1, B2, B3, B4, $\mathrm{C}$, and $\mathrm{D}$ were obtained from Natural Product Institute of Science and Technology (www.nist.re.kr), Anseong, Korea.

\section{Extraction of samples}

Dried and crushed BF (1 kg) was extracted with 70\% EtOH (4 L) under sonication for $1 \mathrm{~h}$ and the process was repeated 2 times. After extraction, the sample was filtered, evaporated at $37{ }^{\circ} \mathrm{C}$, freezedried, and homogenized using $600 \mu \mathrm{m}$ sieve to obtain $70 \% \mathrm{EtOH}$ extract of BF (EEB). Dried and crushed BF $(1 \mathrm{~kg})$ was extracted with water $(4 \mathrm{~L})$ under reflux for $3 \mathrm{~h}$. The resulting extract was filtered using $53 \mu \mathrm{m}$ sieve, evaporated at $37{ }^{\circ} \mathrm{C}$, and homogenized using $600 \mu \mathrm{m}$ sieve to obtain water extract of BF (WEB). The homogenized powders were stored in tight-sealed bottles and kept in a refrigerator with light protection until used for analysis.

\section{Preparation of standards and HPLC conditions}

The EEB and WEB (1 mg each) were dissolved in $\mathrm{MeOH}$ and filtered using a $0.45 \mu \mathrm{m}$ polyvinylidene fluoride (PVDF) membrane filter with the experimental stock solution. One milligram of each standard (saikosaponins A, B1, B2, B3, B4, C, and D) was dissolved in $\mathrm{MeOH}$ by sonicating for $20 \mathrm{~min}$ and filtered through a $0.45 \mu \mathrm{M}$ PVDF membrane filter. Quantitative analysis was performed using a reverse phase HPLC with a YMC Pack Pro $\mathrm{C}_{18}$ column $(5 \mu \mathrm{m}, 25 \mathrm{~cm} \times 4.6 \mathrm{~mm})$. The injection volume was $10 \mu \mathrm{L}$, and the ELS detector was used. The temperature of the column was maintained at $25{ }^{\circ} \mathrm{C}$, and the flow rate was set at 1.1 $\mathrm{mL} / \mathrm{min}$. The eluent used in mobile phase consisted of $90 \%$ acetonitrile (A) and 10\% acetonitrile (B). The lamp discharge system of A started at $20 \%$ until $5 \mathrm{~min}$, increased to $50 \%$ at 35 min, and $100 \%$ at $40 \mathrm{~min}$ which was maintained until $50 \mathrm{~min}$. It was then decreased to $20 \%$ at $51 \mathrm{~min}$ and maintained until $60 \mathrm{~min}$.

\section{Calibration curves}

The standard stock solution was prepared by dissolving the compound in $\mathrm{MeOH}(1 \mathrm{mg} / \mathrm{mL})$. The calibration curve was constructed by continuously diluting the selected stock solutions to the desired concentration. The standard calibration curve values were calculated as peak area $(\mathrm{Y})$, concentration $(\mathrm{X}, \mathrm{mg} / \mathrm{mL})$, and mean value \pm standard deviation $(n=3)$.

\section{Results and Discussion}

BF has been used since ancient times to improve cognitive impairment in people, and compounds isolated from its roots have now been shown to be effective in improving cognitive impairment [3]. Several types of saikosaponins are the main components found in BF [21]. These substances act as therapeutic agents for various diseases and play an important role in improving cognitive ability. Quantitative analyses of saikosaponins A, B1, B2, B3, B4, $\mathrm{C}$, and $\mathrm{D}$ in EEB and WEB were performed using reverse phase HPLC with gradient elution system. The results of our HPLC analyses showed good separation of the components, and the use of ELSD was found to be effective in the detection of saikosaponins. As saikosaponins A, B1, B2, B3, B4, C, and D have no UV chromophores, the optimized analysis was performed at short wavelength of $203 \mathrm{~nm}$ using ELSD owing to the fact that the analysis is susceptible to interference from other substances. The calibration curve was created by linearly plotting peak area vs. prepared concentration and analyzed using linear regression. The linear regression coefficients $\left(r^{2}\right)$ for the standard were 0.9983 to 1 . The calibration curves of saikosaponins A, B1, B2, B3, B4, $\mathrm{C}$, and $\mathrm{D}$ are shown in Table 1.

The structures of saikosaponins A, B1, B2, B3, B4, C, and D are shown in Fig. 1. Peak retention times of 30.7, 33.9, 31.7, 26.8, 27.7, 23.6 and 39.8 min of saikosaponins A, B1, B2, B3, B4, C, and $\mathrm{D}$ are shown in Table 1. HPLC chromatograms of saikosaponins $\mathrm{A}, \mathrm{B} 1, \mathrm{~B} 2, \mathrm{~B} 3, \mathrm{~B} 4, \mathrm{C}$ and $\mathrm{D}$ are shown in Fig. 2. HPLC chromatograms of EEB and WEB are shown in Fig. 3 and 4, respectively. Table 2 shows the content of saikosaponins $\mathrm{A}, \mathrm{B} 1$, B2, B3, B4, C, and D in EEB and WEB. The overall contents of total saikosaponins was 6.085 and $1.93 \mathrm{mg} / \mathrm{mL}$ in EEB and WEB, respectively. The results revealed that $70 \% \mathrm{EtOH}$ was more efficient in extraction of saikosaponins from BF. The parameters affecting extraction efficiency of saikosaponins A, B1, B2, B3, $\mathrm{B} 4, \mathrm{C}$, and D were extraction method and solvent used. In the

Table 1 Calibration curves of saikosaponins A (1), B1 (2), B2 (3), B3 (4), B4 (5), C (6), and D (7)

\begin{tabular}{cccc}
\hline \hline Compound & $\mathrm{t}_{\mathrm{R}}$ & Calibration equation & ${\text { Correlation factor, } r^{2 b}}^{a}$ \\
$\mathbf{1}$ & 30.7 & $\mathrm{Y}=4.3627 \mathrm{X}-50.57$ & $\mathrm{Y}$ \\
$\mathbf{2}$ & 33.9 & $\mathrm{Y}=21.302 \mathrm{X}-1380.9$ & 0.9995 \\
$\mathbf{3}$ & 31.7 & $\mathrm{Y}=5.3135 \mathrm{X}-230.35$ & $\mathrm{Y}=10.937 \mathrm{X}-1209.1$ \\
$\mathbf{4}$ & 26.8 & $\mathrm{Y}=4.3537 \mathrm{X}-633$ & 0.9983 \\
$\mathbf{5}$ & 27.7 & $\mathrm{Y}=16.298 \mathrm{X}-1246$ & 0.9999 \\
$\mathbf{6}$ & 23.6 & $\mathrm{Y}=13.166 \mathrm{X}-1738.5$ \\
$\mathbf{7}$ & 39.8 & & 0.9998 \\
\hline
\end{tabular}

${ }^{a} \mathrm{Y}=$ peak area, $\mathrm{X}=$ concentration of standards $(\mathrm{mg} / \mathrm{mL})$

${ }^{b} r^{2}=$ correlation coefficient based on three data points in the calibration curves 


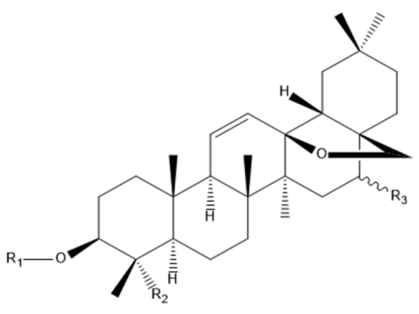

1: $\mathrm{R}_{1}=$ glc-fuc, $\mathrm{R}_{2}=\mathrm{OH}, \mathrm{R}_{3}=\alpha-\mathrm{OH}$

6: $\mathrm{R}_{1}=\operatorname{glc}-\operatorname{rham}(5), \operatorname{glc}(6), \mathrm{R}_{2}=\mathrm{H}, \mathrm{R}_{3}=\alpha-\mathrm{OH}$

7: $\mathrm{R}_{1}=$ glc-fuc, $\mathrm{R}_{2}=\mathrm{OH}, \mathrm{R}_{3}=\beta-\mathrm{OH}$

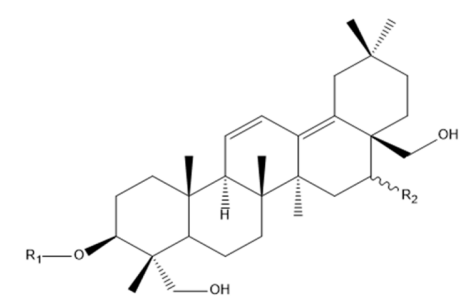

2: $\mathrm{R}_{1}=$ glc-fuc, $\mathrm{R}_{2}=\beta-\mathrm{OH}$

3: $\mathrm{R}_{1}=$ glc-fuc, $\mathrm{R}_{2}=\alpha-\mathrm{OH}$

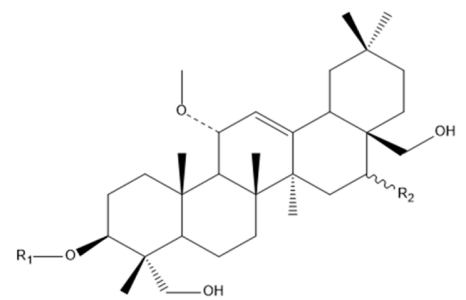

4: $\mathrm{R}_{1}=$ glc-fuc, $\mathrm{R}_{2}=\beta-\mathrm{OH}$

5: $\mathrm{R}_{1}=$ glc-fuc, $\mathrm{R}_{2}=\alpha-\mathrm{OH}$

Fig. 1 Chemical structures of saikosaponins A (1), B1 (2), B2 (3), B3 (4), B4 (5), C (6), and D (7)
Table 2 Contents of saikosaponins A (1), B1 (2), B2 (3), B3 (4), B4 (5), $\mathrm{C}(\mathbf{6})$, and D (7) in EEB and WEB

\begin{tabular}{ccc}
\hline \hline \multirow{2}{*}{ Compound } & \multicolumn{2}{c}{ Content $(\mathrm{mg} / \mathrm{g})$} \\
\cline { 2 - 3 } & EEB & WEB \\
\hline $\mathbf{1}$ & $31.35 \pm 2.19$ & $1.87 \pm 0.04$ \\
$\mathbf{2}$ & $1.78 \pm 0.00$ & $1.70 \pm 0.00$ \\
$\mathbf{3}$ & $1.10 \pm 0.00$ & $2.61 \pm 0.04$ \\
$\mathbf{4}$ & $2.81 \pm 0.00$ & $2.78 \pm 0.01$ \\
$\mathbf{5}$ & $6.31 \pm 0.00$ & $3.64 \pm 0.00$ \\
$\mathbf{6}$ & $5.63 \pm 0.12$ & $2.12 \pm 0.00$ \\
$\mathbf{7}$ & $12.10 \pm 0.29$ & $3.31 \pm 0.01$ \\
\hline
\end{tabular}

extraction method performed using an ultrasonic shaker and $70 \%$ $\mathrm{EtOH}$, the extraction yield was $9.46 \%$. The extraction yield of reflux extraction using water was $20.26 \%$. As shown in Table 2, the content of all standards except saikosaponin B2 were higher in the $70 \% \mathrm{EtOH}$ extract than in the water extract.

Park et al. (2015) previously reported that extraction with $70 \%$ EtOH could increase the content of saikosaponins, consistent with our results [22]. Lee (2008) reported the importance of the extraction solvent during plant extraction. Previous studies on saikosaponin extraction suggested that extracting saikosaponins using $70 \%$ $\mathrm{MeOH}$ and ultrasonic shaker for $40 \mathrm{~min}$ could result in the highest extraction yield. Our results revealed that the saikosaponin content was significantly higher when extracted with $70 \% \mathrm{EtOH}$ than with water. However, we performed water extraction under reflux, and $70 \%$ EtOH extraction using ultrasonic shaker. Consequently, the use of ultrasonic extraction method with water may result in a higher yield of saikosaponins [23].

The overall content of saikosaponins A, B1, B2, B3, B4, C, and $\mathrm{D}$ was higher in the $70 \% \mathrm{EtOH}$ extract than in the water extract. Our study provides an optimized analytical method for determining the best extraction conditions for saikosaponins, which can be used as a basis for development of functional food and pharmaceutical products derived from $\mathrm{BF}$.

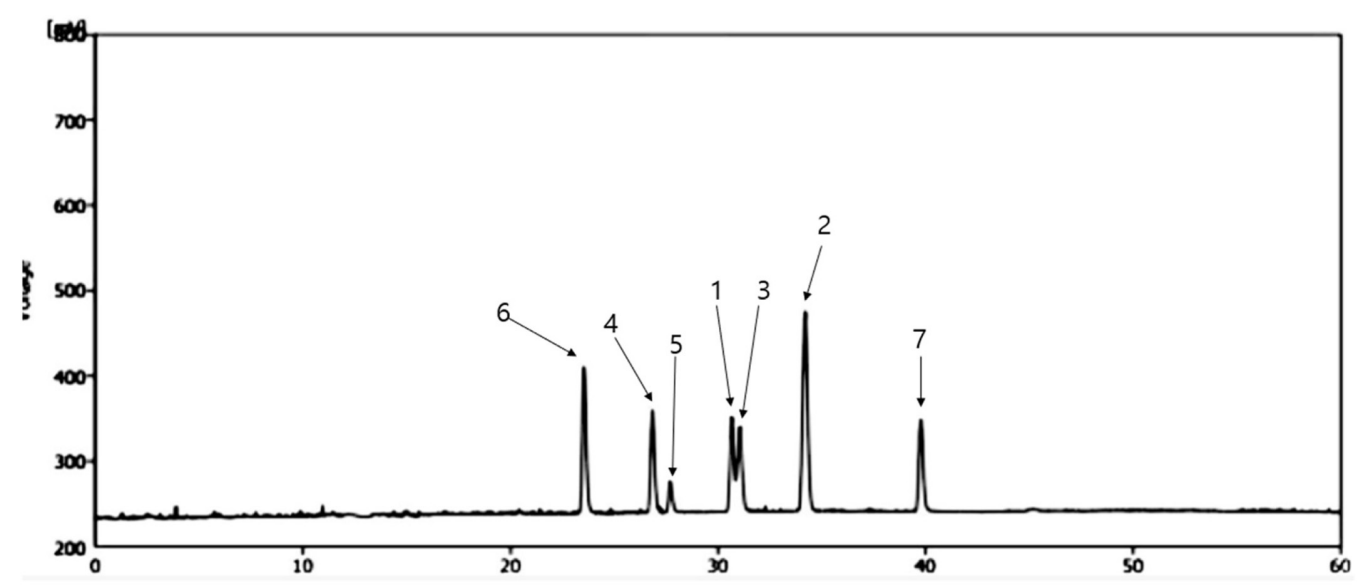

Fig. 2 HPLC chromatogram of saikosaponins A (1), B1 (2), B2 (3), B3 (4), B4 (5), C (6), and D (7) 

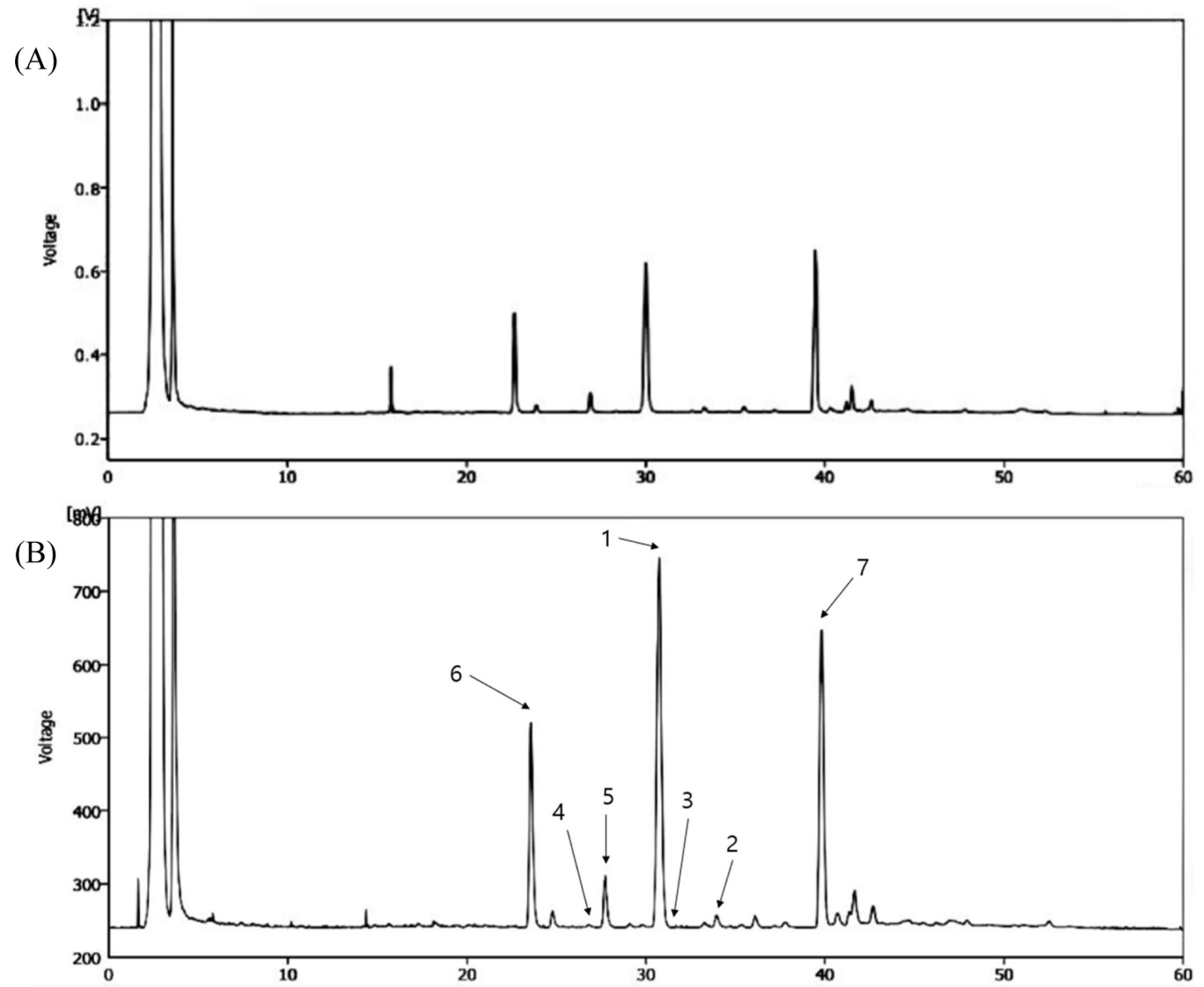

Fig. 3 HPLC chromatograms of EEB (A) and expended EEB (B)

Acknowledgments We would like to thank the Korean Herbarium of Standard Herbal Resources (EEB, 3-19-0097; WEB, 3-19-0054) and Dr. Jin$\mathrm{Mu}$ Yi, Korea Institute of Oriental Medicine, Daejeon 34054, Republic of Korea, for providing the materials. This study was supported by a grant of the Korea Health Technology R\&D Project, through the Korea Health Industry Development Institute (KHIDI) funded by the Ministry of Health \& Welfare (HP20C0226), Republic of Korea.

\section{References}

1. Sun XB, Matsumoto T, Yamada H (1991) Effects of a polysaccharide fraction from the roots of Bupleurum falcatum $\mathrm{L}$. on experimental gastric ulcer models in rats and mice. J Pharm Pharmacol 43: 699-704

2. Yao RU, Zou YF, Chen XF (2013) Traditional use, pharmacology, toxicology, and quality control of species in genus Bupleurum L. Chin Herb Med 5: 245-255

3. Kim MS, Kwon DY, Cho HJ, Lee MS (2006) Protective effects of Korean herbal remedy against oxidative stress in cardiomyocytes. Phytother Res 20: 235-236

4. Lin CC, Chiu HF, Yen MH, Wu CC, Chen MF (1990) The pharmacological and pathological studies on Taiwan folk medicine (III): The effects of Bupleurum kaoi and cultivated Bupleurum falcatum var. komarowi. Am J Chin Med 18: 105-112

5. Shimaoka A, Seo S, Minato H (1975) Saponins isolated from Bupleurum falcatum L.; components of saikosaponin B. J Chem Soc 20: 2043-2048

6. Yamada H, Ra KS, Kiyohara H, Cyong JC, Otsuka Y (1989) Structural characterization of an anti-complementary pectic polysaccharide from the roots of Bupleurum falcatum L. Carbohydr Res 189: 209-226

7. Ebata N, Nakajima K, Hayashi K, Okada M, Maruno M (1996) Saponins from the root of Bupleurum falcatum. Phytochemistry 41: 895901

8. Ono M, Yoshida A, Ito Y, Nohara T (1999) Phenethyl alcohol glycosides and isopentenol glycoside from fruit of Bupleurum falcatum. Phytochemistry 51: 819-823

9. Zong ZP, Yamamoto KF, Ota T, Guan X, Murakami M, Li AL, Yamaguchi N, Tanino M, Odashima S (1998) Saikosaponin B2 induces differentiation without growth inhibition in cultured B16 melanoma cells. Cell Struct Funct 23: 265-272

10. Chen JC, Chang NW, Chung JG, Chen KC (2003) Saikosaponin-A induces apoptotic mechanism in human breast MDA-MB-231 and MCF7 cancer cells. J Chin Med 31: 363-377

11. Shyu K, Tsai S, Wang B, Liu Y, Lee C (2004) Saikosaponin C induces endothelial cells growth, migration and capillary tube formation. Life Sci 76: 813-826

12. Zhu J, Luo C, Wang P, He Q, Zhou J, Peng H (2013) Saikosaponin A mediates the inflammatory response by inhibiting the MAPK and NF- $\kappa$ B pathways in LPS-stimulated RAW 264.7 cells. Exp Ther Med 5: 13451350

13. Shibata S, Kitagawa I, Fujimoto H (1966) The chemical studies on oriental plant drugs. XV. On the constituents of Bupleurum spp. (2). The structure of saikogenin A, a sapogenin of Bupleurum falcatum L. Chem Pharm Bull 14: 1023-1033

14. Yuan B, Yang R, Ma Y, Zhou S, Zhang X, Liu Y (2017) A systematic review of the active saikosaponins and extracts isolated from Radix Bupleuri and their applications. Pharma Boil 55: 620-635

15. Ran X, Gia C, Seiichi PT (2004) On the origins of triterpenoid skeletal 

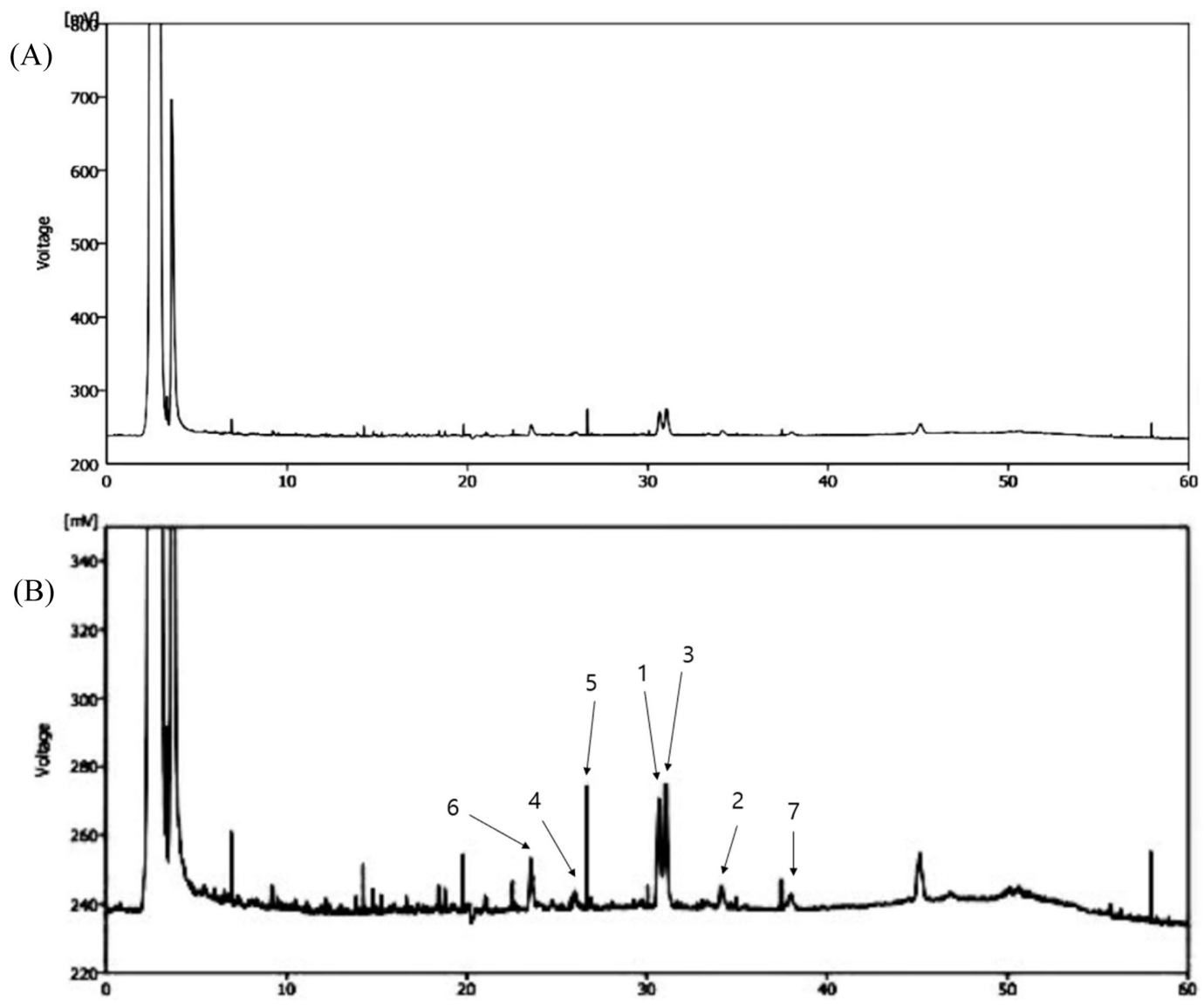

Fig. 4 HPLC chromatograms of WEB (A) and expended WEB (B)

diversity. Phytochemistry 65: 261-291

16. Sun Y, Cai TT, Zhou XB, Xu Q (2009) Saikosaponin a inhibits the proliferation and activation of $\mathrm{T}$ cells through cell cycle arrest and induction of apoptosis. Int Immunopharmacol 9: 978-983

17. Yamada H, Hirano M, Kiyohara H (1991) Partial structure of an antiulcer pectic polysaccharide from the roots of Bupleurum falcatum $\mathrm{L}$. Carbohydr Res 219: 173-192

18. Feng L, Liu L, Zhao Y, Zhao R (2017) Saikosaponins A, C and D enhance liver-targeting effects of anticancer drugs by modulating drug transporters. Oncotarget 8: 110092-110102

19. Park KH, Park J, Koh D, Lim Y (2002) Effect of saikosaponin-A, a triterpenoid glycoside, isolated from Bupleurum falcatum on experimental allergic asthma. Phytother Res 16: 359-363

20. Leung CY, Liu L, Wong RNS, Zeng YY, Li M, Zhou H (2005)
Saikosaponin-D inhibits $\mathrm{T}$ cell activation through the modulation of $\mathrm{PKC} \theta$, JNK, and NF- $\mathrm{KB}$ transcription factor. Biochem Biophys Res Commun 338: 1920-1927

21. Takagi K, Shibata M (1969) Pharmacological studies on Bupleurum falcatum L. acute toxicity and central depressant action of crude saikosides. Yakugaku Zasshi 89: 712-720

22. Park WH, Kang S, Piao Y, Pak CJ, Oh MS, Kim J, Kang MS, Pak YK (2015) Ethanol extract of Bupleurum falcatum and saikosaponins inhibit neuroinflammation via inhibition of NF-KB. J Ethnopharmacol 4: 37-44

23. Lee JH (2009) Simultaneous determination of saikosaponins in Bupleuri Radix by high performance liquid chromatography evaporative light scattering detection and liquid chromatography - mass spectrometry. Dissertation, Chung-Ang University 